\title{
STRATEGI PEMBELAJARAN SENI TARI PADA ANAK DISABILITAS PADA SANGGAR SEKAR DEWATA DESA SERONGGA KECAMATAN GIANYAR KABUPATEN GIANYAR
}

\author{
Oleh: \\ Ni Nyoman Wahyu Adi Gotama \\ mangwin@gmail.com \\ Dosen Fakultas Pendidikan, UNHI Denpasar \\ Komang Agus Triadi Kiswara \\ aguskiswara@gmail.com \\ Dosen Fakultas Pendidikan, UNHI Denpasar
}

\begin{abstract}
ABSTRAK
Disabilitas merupakan suatu ketidakmampuan tubuh dalam melakukan suatu aktifitas atau kegiatan tertentu sebagaimana orang normal pada umumnya yang disebabkan oleh kondisi ketidakmampuan dalam hal fisiologis, psikologis dan kelainan struktur atau fungsi anatomi, dahulu disabilitas lebih dikenal oleh masyarakat dengan sebutan penyandang cacat. maka sanggar tari Sekar Dewata yang ada di desa Serongga Kabupaten gianyar melakukan sebuah tindakan guna mengembalikan fungsi social anak disabilitas dalam penelitian ini mengkaji tiga hal yaitu 1)mengapa strategi penting dalam pembelajaran seni tari disanggar sekar dewata desa serongga kecamatan serongga kab.gianyar2) bagaimana bentuk strategi pemebelajaran seni tari bagi anak disabilitas disanggar sekar dewata? 3) bagaimana implikasi dari penerapan strategi pembelajaran senitari di sanggara sekar Deawata? Penelitian ini mengunakan metode penelitian kualitatif dimana data yang dikumpulkan berupa kata-kata. Teori yang dipergunakan dalam penelitian ini adalah 1) Teori fenomenologi 2)teori fungsional structural 3) teori behaviorisme. Hasil penelitian ini adalah 1) pentingnya peranan strategi dalam pembelajaran seni tari di Sanggar Sekar Dewata adalah a. Alasan budaya budaya memandang bahwasanya seni tari merupakan kegiatan yang sangat lekat dengan kehidupan masyarakat Bali baik dalam kehidupan social maupun kehidupan beragama. B. alas an social manusia dipantang sebagai mahluk social sehingga untuk mengembalikan fungsi social tersebut diperlukan sebuah perencanaan (strategi) c. alas an ekonomi dimana keterampilan yang dimiliki anak disabilitas dapat menjadi jembatan perekonomian. 2 Bagaimana penerapan pembelajaran seni tari yaitu dibagi menjadi beberapa sub. A. proses memperkenalkan ragam jenis tari b. penentuan jenis tari yang akan diberikan. $\mathrm{C}$. latihan dasar dalam sebuah tari. D. pembelajaran tari secara utuh. Dalam proses juga di dukung oleh factor internal dan eksternal. 3. Metode yang dipakai adalah metode a. metode demonstrasi, 2. Metode driil. 3. Adalah metode imitasi.

Kata Kunci: Pembelajaran, Seni tari, Disabilitas
\end{abstract}




\begin{abstract}
Disability is an inability of the body to carry out certain activities or activities as normal people in general are caused by a condition of disability in terms of physiological, psychological and structural abnormalities or anatomic functions. Disability was formerly better known by people as people with disabilities. then the Sekar Dewata dance studio in Serongga village, gianyar district took an action to restore the social function of children with disabilities in this study examines three things, namely 1) why an important strategy in dance learning is violated by sekar dewata village, Serongga village, Serongga district, Kab.gianyar2) dance learning strategies for children with disabilities violated by sekar dewata? 3) what are the implications of implementing the senitari learning strategy at Sanggara Sekar Deawata? This study uses qualitative research methods where data collected in the form of words. Theories used in this study are 1) Phenomenology theory 2) Structural functional theory 3) Behaviorism theory. The results of this study are 1) the importance of the role of strategy in learning dance in Sanggar Sekar Dewata are a. Cultural reasons see that dance art is an activity that is very closely related to Balinese life both in social and religious life. B. human social reasons are challenged as social creatures so to restore the social function is needed a plan (strategy) c. economic reasons where the skills possessed by children with disabilities can be an economic bridge. 2 How is the application of dance learning that is divided into several sub. A. the process of introducing various types of dance $b$. determining the type of dance to be given. C. basic training in a dance. D. dance learning in its entirety. The process is also supported by internal and external factors. 3. The method used is a method. demonstration method, 2. Driil method. 3. Is the method of imitation.
\end{abstract}

Keywords: Learning, dance, disability

\section{PENDAHULUAN}

Disabilitas merupakan suatu ketidakmampuan tubuh dalam melakukan suatu aktifitas atau kegiatan tertentu sebagaimana orang normal pada umumnya yang disebabkan oleh kondisi ketidakmampuan dalam hal fisiologis, psikologis dan kelainan struktur atau fungsi anatomi, dahulu disabilitas lebih dikenal oleh masyarakat dengan sebutan penyandang cacat. Menurut WHO, disabilitas adalah suatu

ketidakmampuan melaksanakan suatu aktifitas atau kegiatan tertentu sebagaimana layaknya orang normal, yang disebabkan oleh kondisi kehilangan atau ketidakmampuan baik psikologis, fisiologis maupun kelainan struktur atau fungsi anatomis. Disabilitas adalah ketidakmampuan melaksanakan suatu aktivitas/kegiatan tertentu sebagaimana layaknya orang normal yang disebabkan oleh kondisi impairment (kehilangan atau ketidakmampuan) yang berhubungan 
dengan usia dan masyarakat (Glosarium Penyelenggaraan Kesejahteraan Sosial 2009).

Hal ini yang tentunya mendorong sanggar-sanggar tari yang ada di Kabupaten gianyar untuk menerima peserta didik anak disabilitas. Gianyar yang merupakan Kota Seni, bahkan ada sebuah jargon Bahwa Gianyar adalah gudangnya seni, tentu sebuah hal yang arif dan bijaksana ketika mencoba dengan metode tertentu untuk dapat memberikan keterampilan pada anakanak disabilitas. Sehingga fungsi social anak disabilitas bisa di optimalkan.

Dalam hal ini pembelajaran seni tari pada anak-anak disabilitas tentunya tidak sama dengan pembelajaran seni tari pada anak-anak umunya dibutuhkan sebuah strategi yang cukup baik sehingga proses pembelajaran mampu berjalan dengan maksimal. Strategi disini berfungsi sebagai road map pembelajaran tari tersebut.

\section{PEMBAHASAN}

\subsection{Pentingnya Strategi Pembelajaran}

Seni Tari Pada Anak Disabilitas di Sanggar Sekar Dewata Desa Serongga Kecamatan Gianyar Kabupaten Gianyar.

Manusia senantiasa diharapkan untuk selalu dapat menjadi pribadi yang sempurna dalam hal ini mampu memenuhi unsur-unsur sebagai manusia diantaranya adalah mampu untuk dapat berkembang baik secara fisik maupun psikologis. Namun dalam kenyataaanya ada beberapa hal yang menyebabkan manusia memeiliki kelambatan dalam perkembanganya yang biasa disebut disabilitas. Dalam beberapa hal manusia juga dipandang dari sudut ketuhanan merupakan mahluk ciptaan tuhan yang paling sempurna.

Bebebrapa penjelasan terkait dengan manusia diatas merupakan hakikat terkait dengan manusia namun demikian anak disabilitas memeiliki beberpa kekurangan terkait dengan hakikat manusia tersebut. Sehingga anakdisabilitas perlu diberikan pembelajarana terkait dengan perkembanganya sebagai manusia yang utuh. Dalam pembelajaran seni tari ada beberapa alasan yang penting mengapa anak disabilitas perlu diberikan pembelajaran kerawitan. Setidaknya ada tiga alasan yang penting terkait dengan pembelajaran karawitan diberikan diantaranya adalah :

\subsubsection{Alasan Budaya}

Kebudayaan berasal dari bahasa sansekerta “ Budhayah" yang berarti budi atau akal. Dalam bahasa latin, budaya berasal dari kata "Colere" yang berarti mengolah tanah. Jadi kebudayaan secara 
umum dapat diartikan sebagai segala sesuatu yang dihasilkan oleh akal budi (pikiran) manusia dengan tujuan untuk mengolah tanah atau tempat tinggalnya. Atau dapat pula diartikan segala usaha manusia untuk mempertahankan dan melangsungkan hidupnya didalam lingkungannya. Kebudayaan merupakan hasil karya, rasa dan cipta masyarakat .

Kebudayaan mengatur supaya manusia dapat mengerti bagaimana seharusnya bertindak, berbuat menentukan sikapnya kalau mereka berhubungan dengan orang lain. Seperti apa yang dikatakan Kluckhohn dan Kelly bahwa "Budaya berupa rancangan hidup" maka budaya terdahulu itu merupakan gagasan prima yang kita warisi melalui proses belajar dan menjadi sikap perilaku manusia berikutnya yang kita sebut sebagai nilai budaya.

Strategi pembeajaran seni tari kepada anaka disabilitas merupakan sebuah upaya yang dilakukan untuk mengembalikan fungsi manusia sebagai mahluk berbudaya. Peranan seni tari dalam kebudayaan Bali tentumemiliki andil yang cukup besar, terlebih dalam keagamaan hindu peranan seni tari sebagai sarana upacara sangan penting, sehingga anak disabilitas dapat memenuhi kembali unsur kebudayaan mereka.

\subsubsection{Alasan Sosial}

Adapun hubungannya dengan manusia sebagai mahluk sosial adalah bahwa dalam mengembangkan potensi-potesinya ini tidak akan terjadi secara alamiah dengan sendirinya, tetapi membutuhkan bantuan dan bimbingan manusia lain. Selain itu, dalam kenyataannya, tidak ada manusia yang mampu hidup tanpa adanya bantuan orang lain. Hal ini menunjukan bahwa manusia hidup saling ketergantungan dan saling membutuhkan antara yang satu dengan lainnya.

Anak disabilitas merupakan pribadi yang perlu mendapatkan dukungan dalamkehidupan sehingga memiliki kemampuan dalam mengembakan diri mereka sebagai individu disinilah peranan penting orang tua dan juga pendidik untuk dapat memberikan bantuan tersebut. Strategi merupakan cara atau siasat yang dipergunakan oleh pelatih kepada peserta didiknya dengan harapan materi yang disampikan dapat diterapkan sesuai dengan harapan. Analisa yang dilakukan pertama adalah dengan memandang anak disabilitas tersebut sebagai mahluk social sehingga dalam kenyataannya mereka juga harus diperlakukan layaknya mahluk social kendatipun dalamkenyataanya mereka juga 
memiliki sisi lemah sehingga peneraoan strategi harus memandang sisi social mereka.

\subsubsection{Alasan Ekonomi}

Manusia dan ekonomi saling berkaitan satu sama lain, hal ini disebabkan karena manusia ini adalah pelaku utama dari kegiatan ekonomi.Mengapa? karena seiring peradaban manusia yang terus berkembang, maka ekonomi pun akan ikut berkembang seiring berjalannya waktu. Hal ini dapat kita lihat dikehidupan kita sehari-hari, di mana manusia pasti membutuhkan barang ataupun jasa yang dapat memenuhi kebutuhan dan keinginannya. Namun terkadang dalam memenuhi kebutuhannya tersebut kadang manusia dihadapi dengan berbagai masalah, masalah yang paling mendasar adalah masalah kelangkaan (scarcity). Oleh karena itu manusia dan ekonomi tidak dapat di pisahkan, karena secara otomatis manusia adalah penggerak dari kegiatan ekonomi itu sendiri dan manusia pun akan mendapatkan hasil dari kegiatan ekonomi yang ia lakukan.

Pembelajaran seni tari bagianak-anak disabilitas adalah sebagai salah satu upaya untuk memberikan keterampilan pada mereka sehingga dapat dipergunakan di masyarakat. Perkembangan kesenian di Bali sangat pesat seni tari adalah salah satu bagian dari keseian dan juga kebudayaan yang ada di Bali. Bila kita amati sangat banyak sekali ikon pariwisata yang menjadikan karawitan sebagai salah satu dari menu pariwisata yang dapat dinikmati oleh para wisatawan.

Hal ini memberikan peluan pada anak disabilitas dengan keterampilan yang mereka miliki kelak mereka akan mampu memenuhi kebutuhan kehidupan mereka sehingga dapat mandiri dengan keterampilan yang mereka miliki.

\subsection{Penerapan strategi Pembelajaran Seni} Tari Bagi anak disabilitas di sanggar sekar dewata Desa Serongga Kabupaten Gianyar.

Dalam penerapan strategi pemebalajaran seni karawitan di SLB C Tabanan ada bebrapa langkah yang dilakukan diantaranya Proses pembelajaran dan metode yang diapakai.

\subsubsection{Proses Pemebelajaran Seni tari Pada anak disabilitas di Sanggar Sekar Dewata.}

Dalam proses pembelajaran tari di Sanggar Sekar Dewata pada anak disabilitas terdapat langkah- langkah yang harus dilakukan seperti sebagai berikut: 


\section{Pengenalan Ragam Seni Tari}

Pada proses ini awalnya anak-anak disabilitas hanya diajak untuk menyaksikan pementasan seni tari yang dipentaskan di sanggar sekar dewata kegiatan ini bertujuan untuk memancing minat anak-anak tersebut sekaligus sebagai motivator dalam kegiatan latihan selanjutnya. .

2. Penentuan jenis tarian yang akan dilatihkan kepada pesertadidik.

Proses ini diadakan untuk mempermudah anak-anak disabilitas dalam melaksanakan latihan tentunya dalam pemebelajaran seni tari memiliki tingkat kesulitan yang cukup kompleks agar anakanak disabilitas tidak kaget dalam proses latihan sehingga pembelajaran seni taripun dilaksanakan secara bertahap dari yang termudah hingga yang cukup sulit.

3. Latihan Dasar dalam sebuah tarian.

Dalam proses ini anak disabilitas dilatih untuk melakukan gerakan-gerakan dasar yang dipergunakan dalam tarian seperti Agem, tandang, tangkis, sledet, nayog, malpal. Dimana gerakan-gerakan ini merupakangerakan pokok yang dipergunakan dalam sebuah tarian. Dalam bentuk selanjutnya biasanya gerakan ini akan disesuaikan denganjenis tarinya.

\section{Pembelajaran Tarian Secara Utuh}

Pembelajaran tarian secara utuh ini merupakan kelajutan dari pemebelajaran dasar. Setelah peserta didik dirasa cukup mampu untuk memahami latihan dasar maka pembelajaran selanjutnya adalah peserta didik akan diberikan bentuk-bentuk tarian

Berjalannya proses pembelajaran seni tari bagi anak disabilitas disanggar sekar dewata juga ditentukan oleh dua factor yaitu factor internal dan factor eksternal diantaranya adalah :

\section{Faktor Internal}

yaitu factor dari dalam, factor dari dalam yang dimaksud disini adalah baik dari dalam peserta didik mapun dari sanggar sendiri:

\section{Tujuan}

Pembelajaran seni tari yang diadakan untuk anak disabilitas ini memiliki tujuan yang jelas yaitu sebagai sarana untukmengembalikan kehidupan social mereka sehingga anak-anak disabiitas memiliki kepercayaan diri yang cukup kuat ketika harus berhadapan dengan peserta didik.

2. Ketersediaan Pengeajar 
Ketersediaan pengajar disanggar sangat berpengaruh bagi keberlangsungan proses pembelajaran, hal ini dikarenakan untuk dapat mengajar anak-anak disabilitas tidak hany diperlukan penguasaan materi akan tetapi juga tingkat kesabaran yang cukup, halini dikarenakan anak-anak disabilitas anak-anak yang memiliki kekurangan seperti anak-anak pada umumnya.

\section{Siswa}

Peserta didik di sanggar sekar dewata yang mengikuti pembelajaran merupakan anak-anak campuran dalamartian anak disabilitas yang berda diwilayah gianyar dan sekitarnya proses seleksi biasanya dilakukan secaraalamiah anak-anak yang memiliki ketertarikan sudah terlihat dari awalmerekamenonton tarian disanggar sekardewata,

Adalah Faktor dari luar peserta didik yang juga turut memberikan kontribusi dalam pemebelajaran seni tari bagi anak disabilitas salah yaitu :

1. Dukungan keluarga.

. Keterlibatan orang tua dalam pembelajaran seni tari disanggar sekar dewata yaitu dengan diajaknya orang tua berdiskusi terkait dengan perkembangan anaknya sehingga

mempermudah

dalam

mengarahkan anak tersebut.

\section{Sarana Prasarana.}

Sanggar sekar dewata memiliki sara dan prasarana yang cukup memadai dengan alatalat untuk memutar kasete sebagai alat latihan dengan situasi studio yang cukup bias menampung anak-anak menari. Namun demikian menurut keterangan pelatih masih diperlukanya bantuan untuk lebih meajukan lagi sarana-dan prasarana tersebut.

\subsubsection{Metode Pembelajaran Seni tari di} Sanggar Sekar Dewata Desa Serongga

\section{Kabupaten Gianyar.}

Dalam pembelajaran di Sanggar Sekar Dewata menggunakan beberapa metode pembelajaran yaitu, demonstrasi, tanya jawab, latihan terus menerus atau dril metode imitasi dan metode pengulangan. Adapun penjelasan metode tersebut adalah sebagai berikut :

\section{Metode Demonstrasi}

Metode ini digunakan oleh pelatih pada saat memberi contoh menari dimana siswa memperhatikan dengan seksama. Metode ini sangat efektif diterapkan pada pembelajaran seni tari pada anak disabilitas karena keterbatasan anak disabilitas untuk 
berkomunikasi jadi mereka cenderung melihat dan menirukan.

\section{Metode Latihan atau Drill}

Metode drill atau latihan berulangulang sangat penting dalam pembelajaran seni tari ini ini. Khususnya bagi anak yang kurang berbakat dan kurang cerdas diperlukan latihan berulang-ulang. Namun rata-rata peserta didik memerlukan latihan berulang-ulang karena dalam pembelajaran seni tari ini perlu mengingat waktu memulai tarian harus selaras dengan iringan.

\section{Metode imitasi}

Metode imitasi adalah cara penyajian bahan pelajaran dimana seorang guru memberikan contoh suatu proses yang sedang dipelajari disertai penjelasan lisan kemudian siswa menirukan. Metode ini cukup efektif digunakan dalam pembelajaran seni tari pada anak disabilitas karena kebanyakan anak-anak disabilitas cenderung menirukan.

\section{Metode Mengulang (rehearsal strategies)}

Agar terjadi pembelajaran, pembelajar harus melakukan tindakan pada informasi baru dan menghubungkan informasi baru tersebut dengan pengetahuan awal. Strategi yang digunakan untuk proses pengkodean ini disebut mengulang.

\subsubsection{Implikasi Strategi Pembelajaran Seni Tari pada anak disabilitas di Sanggar Sekar Dewata Desa Serongga Kabupaten Gianyar.}

Setiap orang menginginkan yang terbaik dalam kehidupan ini tanpa terkecuali hal ini sesuai dengan (bhagavad gita III.42)

Indriyani paraany aahur

\section{Indriyebhyah param manah}

Manasas tu paraa budhir

Yo buddheh paratas tu sah

Artinya : indria itu agar diperkuat tetapi agar lebih kuat lagi pikiran lebih kuat dari pikiran (manah) adalah intelek (budhi) lebih kuat lagi Atman.

Diri itu adalah keberadaan manusia seutuhnya baik lahir maupun bathin. Dengan kata lain diri itu adalah keberadaan manusia dengan segala totalitasnya tanpa terkecuali. Bagi anak disabilitas sangat penting diterapkan sebuah pemebelajaran dimana tidak hanya mampu melatih diri semata akan tetapi juga mampu untuk mentajamkan intelektualisat mereka. 
Kembalinya fungsi sosialanak disabilitas

\begin{abstract}
Manusia sebagai mahkluk sosial dalam kehidupan sehari-harinya pasti membutuhkan orang lain. Proses interaksi dan sosialisasi selalu terjadi kapan dan dimanapun manusia itu berada. Dalam hal ini bentuk interaksi sosial sangat bermacammacam. Adapun pengertian interaksi sosial menurut Effendi (2010:46) adalah kata interaksi berasaldari kata inter dan action. Interaksi sosial adalah hubungan timbal balik saling mempengaruhi antar individu, kelompok social, dan masyarakat.
\end{abstract}

Yang ketiga yaitu Identifikasi, dalam psikologis identifikasi berarti dorongan untuk menjadi identik atau dorongan untuk menjadi sama dengan orang lain, baik secara lahir maupun batin. Faktor yang keempatyaitu simpati, simpati yaitu perasaaan yang timbul pada orang lain atas dasar penilaian menurut perasaan didalam dirinya. Dalam pembelajaran seni tari pada anak disabilitas anak akan belajar bagaimana bekerjasaman saling bertegur sapa, sehingga anak secara tidak langsung belajar terkait interaksi social.

\section{Anak disabilitas lebih di terima}

\section{Masyarakat}

Krech, Crutchfield, dan Ballachey (Effendi, 2010: 59) mengemukakan devinisi masyarakat sebagai "a society is that it is an organized collectivity of interacting people whose actives become centered around a set of common goals, and who tend to share common beliefs, attitudes, and of action." Dari devinisi tersebut dapat ditarik kesimpulan unsur-unsur yanga ada dalam masyarakat adalah kolektivitas interaksi manusia yang terorganisasi, kegiatannya yang terarah pada sejumlah tujuan yang sama, memilikin kecenderungan untuk memiliki keyakinan, sikap, dan bentuk tindakan yang sama. Dalam hal ini, interkasi dan tindakan itu tentu saja interaksi serta tindakan sosial.

Menurut konsep di atas, karakteristik dari masyarakat itu adalah adanya sekelompok manusia yang menunjukan perhatian bersama secara mendasar, pemeliharaan kekekalan bersama, perwakilan menusia menurut sejenisnya yang berhubungan satu sama lain secara berkesinambungan. Dengan demikian, relasi manusia sebagai suatu bentuk masyarakat itu tidak terjadi dalam waktu yang singkat, melainkan secara berkesinambungan dalam waktu yang relatif cukup lama.

Dengan keterampilan yang dimiliki akan memberikan pandangan yang berbeda kepada anak disabilitas dimana yang pada 
umumnya anak disabilitas dianggap tidak dapat melakukan apa-aopa dengan keterampilan yang dimiliki tentu akan meberikan pandangan yang baru, dimana jika diberikan kesempatan yang sama anakanak dengan kebutuhan khusus juga dapat melakukan hal tersebut.

\section{PENUTUP}

1. Alasan pentingnya anak disabilitas diberikan pembelajaan seni Tari adalah secara budaya anak disabilitas mampu mengembalikan fungsi budayanya juga mengajarkan anak disabilitas untuk dapat mengembangkan fungsi sosialnya. Fungsi ekonomi seni kerawitan merupakan bekal keterampilan bagi anak-anak disabilitas

2. Pelaksanaan Pemebelajaran seni karawitan di SLB C tabanan secara umum pemebelajaran seni karawwitan di SLB c Tabanan di bagi menjadi 2 yaitu pertama adalah pelaksanaan pemebelajaran yang meliputi, pengenalan alat music,kedua penentuan alat music, ketiga latihan membunyikan, ketiga memaikan lagu kemudian tahap kedua adalah penerapan metode adapun metode yang dipergunakan adalah : Metode demonstrasi, metode latihan (driil), metode imitasi, dan metode mengulang

3. Implikasi dari pemebelajaran seni kerawitan adalah kembalinya fungsi social anak-anak disabilitas sebagai mahluk individu perkembangan anak disabilitas cenderung susah untukmampu beradaptasi dan mengembangkan sikapsosialnya dengan pemebelajaran kerawitan anak disabilitas diajarkan untuk dapat berinteraksi dan mengembangkan social individunya. Kedua adalah anakdisabilitas lebih mampu diterima di masyarakat pandangan masyarakat yang selalu mamndang sebelah mata anak disabilitas dengan keterampilan yang mereka miliki akan memeberikan ruang yang cukup luas untuk anak disabilitas lebih berkembang di masyarakat.

\section{DAFTAR RUJUKAN}

Affandi, M. 1991. Strategi Pembelajaran Seni Rupa. Yogyakarta : UPPKL IKIP.YK.

Asnawir. 2002. Media Pembelajaran. Jakarta : Ciputat Press. 
Bahari, Nooryan. 2008. Kritik Seni, Wacana Apresiasi dan Kreasi. Yogyakarta : Pustaka Pelajar.

Bratanata, S.A. 1977. Pendidikan anakanak terbelakang untuk SGPLB. Bandung: Masa Baru. 1997. Pendidikan Anakanak Berkelainan. Jakarta : Departemen Pendidikan Dan Kebudayaan.

Dwijo Sumarto, Andreas, Drs. Dan Amin, Moh, Drs. 1979. Pendidikan Luar Biasa. Jakarta : PT New Aqua Express.

Hamalik, Oemar. 2003. Proses Belajar Mengajar. Jakarta : Bumi Aksara. . 2005. Kurikulum dan pembelajaran. Jakarta : Bumi Aksara.

Handoyo, Cipto, Budi. 2010. Penelitian Pendidikan Sebuah Adaptasi Model

Untuk Bidang Seni Musik. Yogyakarta : Kanwa Publisher.

Hasibuan. 2002. Proses Belajar Mengajar. Bandung : PT Remaja Rosdakarya.
, J. J., Ibrahim, dan Tolience, A. J. E. (1988). Proses Belajar mengajar

Khisbiyah, Yayah. 2004. Pendidikan Apresiasi Seni ( Wacana dan Praktik untuk Toleransi Pluralisme Budaya). Surakarta : Pusat Studi Budaya dan Perubahan Sosial.

Kodrat, Ki Harsono. 1982. Gending-gending Karawitan Jawa Lengkap SlendroPelog Jilid 1. Jakarta : Balai Pustaka.

Marijani, L. (2003). Bunga Rampai Seputar Autisme dan Permasalahannya. Jakarta :puterakembara Foundation

Moleong, Lexy. 1996. Metodologi Penelitian Kualitatif. Bandung : Remaja Rosdakarya.

Mulyasa. 2007. Kurikulum Tingkat Satuan Pendidikan. Bandung : PT Rosda

Karya. 